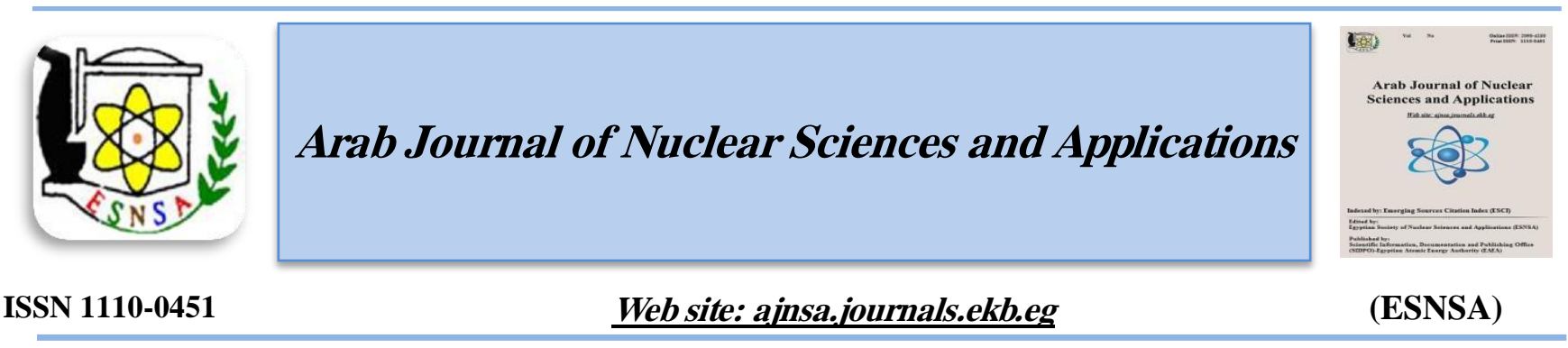

\title{
A Suggested Modification of the Fundamental Parameter Method: A Case Study to Calculate the Optimum Absolute Intensity of $1001.03 \mathrm{keV}$ Gamma- Ray Transition
}

\author{
Ashraf E.M. Khater ${ }^{1}$ and Yasser Y. Ebaid ${ }^{2}$ \\ ${ }^{1}$ Nuclear Safeguards and Physical Protection Department, Nuclear and Radiological Regulatory Authority, Cairo, \\ Egypt \\ ${ }^{2}$ Physics Department, Faculty of Science, Fayoum University, Fayoum, Egypt
}

\begin{abstract}
Received $2^{\text {th }}$ Apr. 2019 The fundamental parameter method (FPM) is an analytical approach for intrinsic calibration of gammaAccepted $21^{\text {th }}$ May 2019 ray spectrometer using fundamental nuclear and atomic parameters such as gamma-ray branching intensity, half-life time, isotopic ratio and concentration ratio. The main advantage of this approach is the wide range of its applications in gamma-ray efficiency calibration, nuclear safeguards (nuclear materials measurement and isotopic ratios) and others. In this work, the calculation of the relative efficiency (RE: photopeak count rate divided by branching ratio) was modified based on the relative intensity concept of ${ }^{-226} \mathrm{Ra}$ in equilibrium with ${ }^{222} \mathrm{Rn}$ decay products $\left({ }^{214} \mathrm{Bi}^{214} \mathrm{~Pb}\right)$. The modified FPM was applied to reevaluate the absolute intensity (I\%) of gamma-ray transition of ${ }^{234 \mathrm{~m}} \mathrm{~Pa}$ at $1001.03 \mathrm{keV}$ using certified uranium ore samples, ${ }^{226} \mathrm{Ra}$ point source and gamma-ray spectrometers based on hyper pure germanium detector. The newly confirmed I \% of $1001.03 \mathrm{keV}$ is $1.0164 \pm 0.0636$.
\end{abstract}

Keywords: Fundamental parameter method/ $1001.03 \mathrm{keV} /$ Gamma-ray transition/ ${ }^{238} \mathrm{U} / 1001.03 \mathrm{keV}$

\section{Introduction}

The fundamental parameter method was suggested by Eberle et al. as a direct application of peak ratio concept and intrinsic calibration of gamma-ray spectrometer using fundamental nuclear and atomic parameter such as gamma-ray branching intensity (I\%), half-life time, isotopic ratio and concentration ratio. This approach was applied for the measurement of the isotopic ratios of different nuclear materials in the nuclear safeguard field. It was also used to confirm the squallier equilibrium with natural radionuclides (e.g. ${ }^{238} \mathrm{U}$ and ${ }^{232} \mathrm{Th}$ ) series decay products [1]. The RE concept was proposed to use the spectrum of the sample itself to estimate the variation of detector efficiency as a function of energy where $\mathrm{RE}$ is the ratio of photopeak count rate to $\mathrm{I} \%$ of the same gamma-ray transition energy.

The accurate determinations of ${ }^{238} \mathrm{U}$ and other $\mathrm{U}$ isotopes $\left({ }^{235} \mathrm{U}\right.$ and $\left.{ }^{234} \mathrm{U}\right)$ are the backbone of different ${ }^{238} \mathrm{U}$ series disequilibrium applications and nuclear safeguards [2-5]. Gamma-ray spectrometer is one of the widely used nondestructive analytical techniques for determination of $U$ activity concentration and isotopic ratio. For ${ }^{238} \mathrm{U}$, the well resolved gamma-ray transition of ${ }^{234 \mathrm{~m}} \mathrm{~Pa}$ (granddaughter of ${ }^{238} \mathrm{U}$ ) at $1001.03 \mathrm{keV}$ is preferably used because of its minimal selfattenuation and spectral interferences [6-13]. The accurate measurement of gamma-ray emitters lied

Corresponding author: khater ashraf@yahoo.com

DOI: 10.21608/ajnsa.2019.12393.1213

(C) Scientific Information, Documentation and Publishing Office (SIDPO)-EAEA 
on the accuracy of I\% value (also called branching ratio, emission probability and f-value). Earlier, Coursol et al, reported an intensity value of $0.59 \%$ for the $1001.03 \mathrm{keV}$ that was used for $\mathrm{U}$ gammaray evaluation for a while [14]. Nodaway, the commonly used I\% value is $0.847 \pm 0.008 \%$ [15].

Among all the ruling factors affecting the accuracy of gamma-ray spectrometry, I \% relatively overcomes the significance of other parameters. Over decades, various studies have been performed in order to accurately evaluate $\mathrm{I} \%$ of $1001.03 \mathrm{keV}$ gamma-ray transition that varies widely from $0.59 \%$ up to $1.12 \%$ [16-35]. Furthermore, recent studies have suggested that there is a noticeable under estimation of the currently used $\mathrm{I} \%$ of $1001.03 \mathrm{keV}$ gamma-ray transition. The most recent published values of $\mathrm{I} \%$ were $1.037 \pm 0.052$ and $1.067 \pm 0.084$ using both of the absolute and relative efficiency calibration concepts, respectively [36-37].

This study aims at suggesting modification on the FPM, in addition to optimizing and scrutinizing I\% value of the $1001.03 \mathrm{keV}$ gamma-ray transition of the ${ }^{234 \mathrm{~m}} \mathrm{~Pa}$ using MFPM.

\section{A modified fundamental parameter method}

The activity ratios of ${ }^{238} \mathrm{U}$ series members (where the activity ratios amongst them are approximately unity) using gamma-ray spectrometer and energy transitions of ${ }^{234} \mathrm{Th},{ }^{234 \mathrm{~m}} \mathrm{~Pa},{ }^{226} \mathrm{Ra},{ }^{214} \mathrm{~Pb}$ and ${ }^{214} \mathrm{Bi}$, along with the status of $U$ series secular equilibrium can be confirmed using the fundamental parameter method (FPM) that was described in details by Eberle [1]. It does not need standard sources, and it depends on physical parameters such as the absolute intensity and the half-life. The relative efficiency (RE) concept facilitates the generation of a RE curve from the sample itself regardless of their geometry, matrix or activity concentration, taking into consideration some spectrometric vital factors such as intrinsic efficiency of the detector, counting geometry and attenuation in the sample matrix [30]. The principle equation for activity concentration calculation is;

$$
\begin{aligned}
& A=\frac{C}{\varepsilon \times I} \\
& \varepsilon=\frac{C}{A \times I}
\end{aligned}
$$

\section{Where}

$\varepsilon \quad:$ absolute full energy photopeak efficiency, C : count rate (counts/sec) of $1001.03 \mathrm{keV}$ photopeak,

A : activity concentration of ${ }^{238} \mathrm{U}$ in the sample, Becquerel (Bq),

I: absolute intensity \% of $1001.03 \mathrm{keV}$ gamma-ray transition.

Secular equilibrium of natural radionuclides series such as ${ }^{238} \mathrm{U}$ and ${ }^{232} \mathrm{Th}$ series can be confirmed using the activity ratios between series radionuclides utilizing the fundamental parameter method (FPM) and the relative efficiency (RE) concept that is given by;

$$
\begin{aligned}
& \text { Realtive Efficiency, } \operatorname{RE}\left(\mathrm{E}_{\mathrm{i}}\right) \\
& =\frac{\text { net count rate in the photopeak }\left(\mathrm{E}_{\mathrm{i}}\right),(\mathrm{cps})}{\text { Absolute intensity }\left(\mathrm{E}_{\mathrm{i}}\right),(\%)}
\end{aligned}
$$

The details of the FPM were described in another publication by Eberle et al. [1] where the activity ratio of series radionuclides such as ${ }^{234} \mathrm{Th},{ }^{234 \mathrm{~m}} \mathrm{~Pa}$, ${ }^{226} \mathrm{Ra},{ }^{214} \mathrm{~Pb}$ and ${ }^{214} \mathrm{Bi}$ within ${ }^{238} \mathrm{U}$ series can be given by equations (3);

$$
\begin{aligned}
& \frac{A_{i}}{A_{j}}=\frac{C\left(E_{i}\right)}{C\left(E_{j}\right)} \cdot \frac{\varepsilon\left(E_{j}\right)}{\varepsilon\left(E_{i}\right)} \cdot \frac{I\left(E_{j}\right)}{I\left(E_{i}\right)} \\
& \frac{\varepsilon\left(E_{j}\right)}{\varepsilon\left(E_{i}\right)}=\frac{R E\left(E_{j}\right)}{R E\left(E_{i}\right)} \\
& \frac{A_{i}}{A_{j}}=\frac{C\left(E_{i}\right)}{C\left(E_{j}\right)} \cdot \frac{R E\left(E_{j}\right)}{R E\left(E_{i}\right)} \cdot \frac{I\left(E_{j}\right)}{I\left(E_{i}\right)}
\end{aligned}
$$

Where;

$A_{i} \quad$ : The activity ratio of isotopes $i$ and $j$ $\overline{A_{j}} \quad$ with the gamma-ray transitions $E_{i}$ and $E_{j}$ $\mathrm{C}\left(\mathrm{E}_{\mathrm{i}}\right)$ : The net count rate (cps) ratio of $\bar{C}\left(E_{j}\right)$ photopeak of the gamma-ray transitions $\varepsilon\left(\mathrm{E}_{\mathrm{j}}\right) \quad \mathrm{E}_{\mathrm{i}}$ and $\mathrm{E}_{\mathrm{j}}$

$\frac{\varepsilon\left(E_{1}\right)}{\varepsilon}$ : the absolute full energy photopeak efficiency ratio of the gamma-ray transitions $\mathrm{E}_{\mathrm{j}}$ and $\mathrm{E}_{\mathrm{i}}$

$\operatorname{RE}\left(E_{j}\right)$ : The relative efficiency ratio of the $\overline{\operatorname{RE}\left(\mathrm{E}_{\mathrm{i}}\right)}$ gamma-ray transitions $\mathrm{E}_{\mathrm{j}}$ and $\mathrm{E}_{\mathrm{i}}$

$\frac{I\left(E_{j}\right)}{I\left(E_{i}\right)} \quad$ : The absolute intensity ratio of the

In the modified fundamental parameter method (MFPM), the RE of different gamma-ray transitions $(242-2447.86 \mathrm{keV})$ of ${ }^{214} \mathrm{~Pb}^{214} \mathrm{Bi}$, in all 
RGU-1 voluminous samples as well as ${ }^{226} \mathrm{Ra}$ point source were calculated using the following equations instead of equation (2);

$$
\begin{aligned}
& \begin{array}{l}
\text { Reltaive intenisty, } R I\left(E_{i}\right) \\
\text { net count in the photopeak }\left(\mathrm{E}_{i}\right)
\end{array} \\
& =\frac{\text { net count in the photopeak }(609 \mathrm{keV})}{\text { Realtive Efficiency, } \mathrm{RE}\left(\mathrm{E}_{\mathrm{i}}\right)} \\
& \qquad=\frac{\text { Calculated } R I\left(\mathrm{E}_{\mathrm{i}}\right)}{\text { Reference } R I\left(\mathrm{E}_{\mathrm{i}}\right)}
\end{aligned}
$$

Reference $\mathrm{RI}\left(\mathrm{E}_{\mathrm{i}}\right)$ for $\mathrm{Pb}-214-\mathrm{Bi}-214$ is given in other publications $[15,38,39]$.

\section{Experimental work}

Aliquots of the RGU-1 reference sample [40] of different volumes were packed into standard volume cylindrical polyethylene containers. The samples where tightly sealed and put aside for 28 days in order to acquire secular equilibrium between ${ }^{226} \mathrm{Ra}$ and ${ }^{222} \mathrm{R}$ [41]. Gamma ray spectrometers based on extended range HPGe detectors were exploited. They were fully described in a recent work [36].

Samples (RGU-1) were measured for long times (up to one week) in order to insure minimal counting uncertainty in peak area calculation. Four sets of gamma-ray spectrometric measurements were performed for different samples' geometries (30, 40, 56 and $112 \mathrm{cc})$.

Radium-226-point source was measured in nine different systematical positions in circular plane (with $15 \mathrm{~cm}$ diameter) coaxial with and $25 \mathrm{~cm}$ away from the detector's end cap.

Most of the intense energy transition photopeaks of ${ }^{214} \mathrm{~Pb}-{ }^{214} \mathrm{Bi}$, beginning form the energy transition $242 \mathrm{keV}(7.43 \%)$ of the ${ }^{214} \mathrm{~Pb}$ and ending with $2447.86(1.548 \%)$ of ${ }^{214} \mathrm{Bi}$ were exploited and achieved counting errors between $<0.1 \%$ and $0.2 \%$. However, the achieved counting errors for the $1001.03 \mathrm{keV}$ were less than $1 \%$. The RE of each gamma-ray transition was calculated using equation (7), and then the REs were together exploited to generate RE's polynomial fitting curves of $4^{\text {th }}$ or $5^{\text {th }}$ degree for each RGU-1 sample as well as for each ${ }^{226} \mathrm{Ra}$ point source measurement

Fig._(1). Then the polynomial fitting functions were used to calculate the $\mathrm{RE}_{\mathrm{p}}$ values of 1001.03 $\mathrm{keV}$ gamma-ray transition of ${ }^{234 \mathrm{~m}} \mathrm{~Pa}$ and other gamma-ray transitions (609.31, 934.06 and $1120.29 \mathrm{keV})$.
Additionally, I $\left(\mathrm{E}_{\mathrm{j}}\right)$ of $1001.03 \mathrm{keV}\left(\mathrm{E}_{\mathrm{j}}\right)$ gammaray transition was calculated using equation (5) and the parameters $\left[R E_{i}, C\left(E_{i}\right)\right.$ and $\left.I\left(E_{i}\right)\right]$ of the three gamma-ray transitions of ${ }^{214} \mathrm{Bi}$, the most intense gamma-ray transitions are $609.31 \mathrm{keV}$ $(45.49 \%)$, and the closest gamma-ray transitions to $1001.03 \mathrm{keV}$ is $934.06 \mathrm{keV}(2.89 \%)$, and $1120.29 \mathrm{keV}(14.91 \%)$. These three calculated values of I \% will be referred to as different MFPM modes throughout the manuscript.

The details on the sources of uncertainty and their calculations were given in a previous work [36].

\section{Results and Discussion}

The accurate determination of ${ }^{238} \mathrm{U}$ using ${ }^{234 \mathrm{~m}} \mathrm{~Pa}$ gamma-ray transition of $1001.03 \mathrm{keV}$ depends on different parameters such as full energy photopeak efficiency $(\varepsilon)$ and absolute intensity (I\%). One of the most critical parameters is I\% that has been evaluated using different analytical techniques and varied from $0.59 \pm 0.1 \%$ up to $1.12 \pm 0.067 \%$ ) [1635]. The most recent published $\mathrm{I} \%$ value was 1.037 that was about $20 \%$ higher than the commonly used value $0.847 \pm 0.008[15,36,41]$

The descriptive statistics (mean, standard deviation and range) of the absolute intensity of 1001.026 $\mathrm{keV}$ energy transition of the ${ }^{234 \mathrm{~m}} \mathrm{~Pa}$ using different modes of MFPM and different sample's geometry are given in Tables (1 and 2). Their frequency distribution is shown in Fig. (2). There is a noticeable consistency throughout the repeated

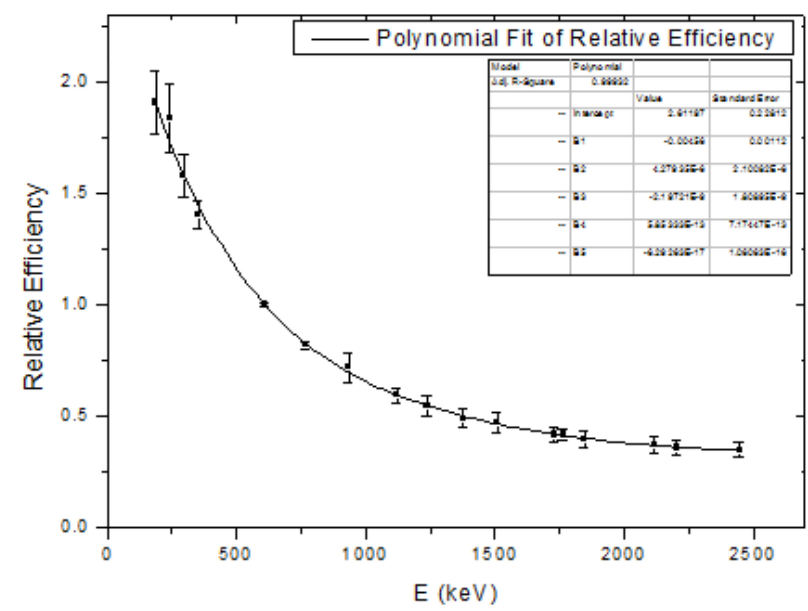

calculations

Fig. (1): The relative efficiency curve as a function of energy (keV) for the different gamma-ray transitions of 214Pb-214Bi (242-2447 keV)

The absolute intensity value (I \%) of ${ }^{234 \mathrm{~m}} \mathrm{~Pa}$ gamma-ray transition at $1001.03 \mathrm{keV}$ using the current approach (MFPM), has resulted in an 
optimum I\% value of $1.0164 \pm 0.0636(0.8554-$ $1.2234)$. The frequency distribution of these data is shown in Fig. (2).

Finally, the overall average \pm SD (range), of the present work as well as that of the previously published works [36,37] (I \% of ${ }^{234 \mathrm{~m}} \mathrm{~Pa}$ gamma-ray transition at $1001.03 \mathrm{keV}$ )using diverse analytical approaches (AEM, FPM and MFPM), gamma-ray spectrometers, sample-detector's geometries and samples' geometries was $1.0385 \pm 0.0771(0.8554$ $1.3024)$
The compilation of an extensive experimental data (736 points) $[36,37]$ on the re-evaluation of $\mathrm{I} \%$ of $1001.03 \mathrm{keV}$ gamma-ray transition using different analytical approaches (AEM, FPM and MFPM), voluminous sources (uranium ore and granite), ${ }^{226} \mathrm{Ra}$ point source, samples' geometries, sampleto-detectors' geometries, samples' physical forms (solid and solution) and gamma ray spectrometers resulted in a new value of $1.0385 \pm 0.0771 \%$.

Table (1): The absolute intensity of $1001.026 \mathrm{keV}$ energy transition of the ${ }^{234 \mathrm{~m}} \mathrm{~Pa}$ using different modes of modified fundamental parameter method (MFPM) for its different modes

\begin{tabular}{|c|c|c|c|c|c|}
\hline \multicolumn{2}{|c|}{ MFPM modes } & $609.31 \mathrm{keV}$ & $934.06 \mathrm{keV}$ & $1120.29 \mathrm{keV}$ & average \\
\hline \multirow{4}{*}{ 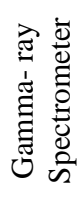 } & \multirow{2}{*}{1} & $0.9890 \pm 0.0741^{+}$ & $1.0056 \pm 0.0354$ & $0.9737 \pm 0.0273$ & $1.0014 \pm 0.0586$ \\
\hline & & (0.8554-1.1458) & $(0.9160-1.0708)$ & $(0.8991-1.0485)$ & $(0.8554-1.2185)$ \\
\hline & \multirow[t]{2}{*}{2} & $1.0527 \pm 0.0620$ & 1.05520 .0634 & 1.02380 .0619 & 1.04390 .0636 \\
\hline & & $(0.9611-1.2234)$ & $(0.9651-1.2185)$ & (0.9197-1.1794) & $(0.9197-1.2234)$ \\
\hline & \multirow{2}{*}{$\begin{array}{c}\text { Voluminous } \\
\text { sample (RGU- } \\
\text { 1) }\end{array}$} & $1.0801 \pm 0.0548$ & $1.0328 \pm 0.0548$ & $1.0136 \pm 0.0585$ & $1.0422 \pm 0.0621$ \\
\hline & & $(0.9724-1.2234)$ & $(0.9444-1.2047)$ & $(0.9377-1.1794)$ & $(0.9377-1.2234)$ \\
\hline & \multirow{2}{*}{$\begin{array}{l}\text { Point source, } \\
{ }^{226} \mathrm{Ra}\end{array}$} & $0.9775 \pm 0.0590$ & $1.0219 \pm 0.0569$ & $0.9840 \pm 0.0438$ & $1.0048 \pm 0.0610$ \\
\hline & & (0.8554-1.1647) & (0.9121-1.2185) & (0.8991-1.1388) & $(0.8554-1.2185)$ \\
\hline \multirow{2}{*}{\multicolumn{2}{|c|}{ Average }} & $1.01633 \pm 0.0758$ & $1.0269 \pm 0.0549$ & $0.9952 \pm 0.0516$ & $1.0164 \pm 0.0636$ \\
\hline & & $(0.8554-1.2234)$ & $(0.9160-1.2185)$ & $(0.8991-1.1794)$ & $(0.8554-1.2234)$ \\
\hline
\end{tabular}

Table (2): The absolute intensity of $1001.026 \mathrm{keV}$ energy transition of the ${ }^{234 \mathrm{~m}} \mathrm{~Pa}$ using different modes of modified fundamental parameter method (MFPM) for different sample's geometries

\begin{tabular}{|c|c|c|c|c|c|}
\hline & Geometry & $112 \mathrm{cc}^{+}$ & $56 \mathrm{cc}$ & $40 \mathrm{cc}$ & $30 \mathrm{cc}$ \\
\hline \multirow{4}{*}{ 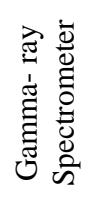 } & \multirow{2}{*}{1} & $0.9776 \pm 0.0426$ & $1.0062 \pm 0.0494$ & $1.0026 \pm 0.0551$ & $0.9814 \pm 0.0578$ \\
\hline & & (0.9377-1.0948) & $(0.9528-1.1657)$ & $(0.9182-1.1458)$ & (0.8554-1.0737) \\
\hline & \multirow{2}{*}{2} & $1.0088 \pm 0.0382$ & $1.0380 \pm 0.0626$ & $1.0828 \pm 0.0752$ & $1.0381 \pm 0.0448$ \\
\hline & & $(0.9245-1.0884)$ & $(0.9197-1.1657)$ & $(0.9615-1.2234)$ & $(0.9448-1.1137)$ \\
\hline \multirow{6}{*}{ : } & \multirow{2}{*}{$\begin{array}{c}\text { Voluminous } \\
\text { sample (RGU- } \\
1 \text { ) } \\
\end{array}$} & $1.0077 \pm 0.0447$ & $1.0387 \pm 0.0568$ & $1.0702 \pm 0.0724$ & $1.0507 \pm 0.0447$ \\
\hline & & $(0.9377-1.0948)$ & $(0.9528-1.1657)$ & (0.9702-1.2234) & $(0.9824-1.1137)$ \\
\hline & \multirow{2}{*}{$\begin{array}{l}\text { Point source, } \\
{ }^{226} \mathrm{Ra}\end{array}$} & $0.9730 \pm 0.0374$ & $1.0010 \pm 0.0494$ & $1.0026 \pm 0.0551$ & $0.9814 \pm 0.0578$ \\
\hline & & $(0.9122-1.0948)$ & $(0.9205-1.1361)$ & $(0.9182-1.1458)$ & $(0.8554-1.0737)$ \\
\hline & \multirow{2}{*}{ Average } & $0.9869 \pm 0.0437$ & $1.0161 \pm 0.0564$ & $1.0347 \pm 0.0748$ & $0.9910 \pm 0.0578$ \\
\hline & & $0.9122-1.0948)$ & $(0.9197-1.1657)$ & $(0.9182-1.2234)$ & $(0.8554-1.0878)$ \\
\hline & \multirow{2}{*}{ Average ${ }^{x}$} & \multicolumn{4}{|c|}{$1.0164 \pm 0.0636$} \\
\hline & & \multicolumn{4}{|c|}{ (0.8554-1.2234) } \\
\hline
\end{tabular}




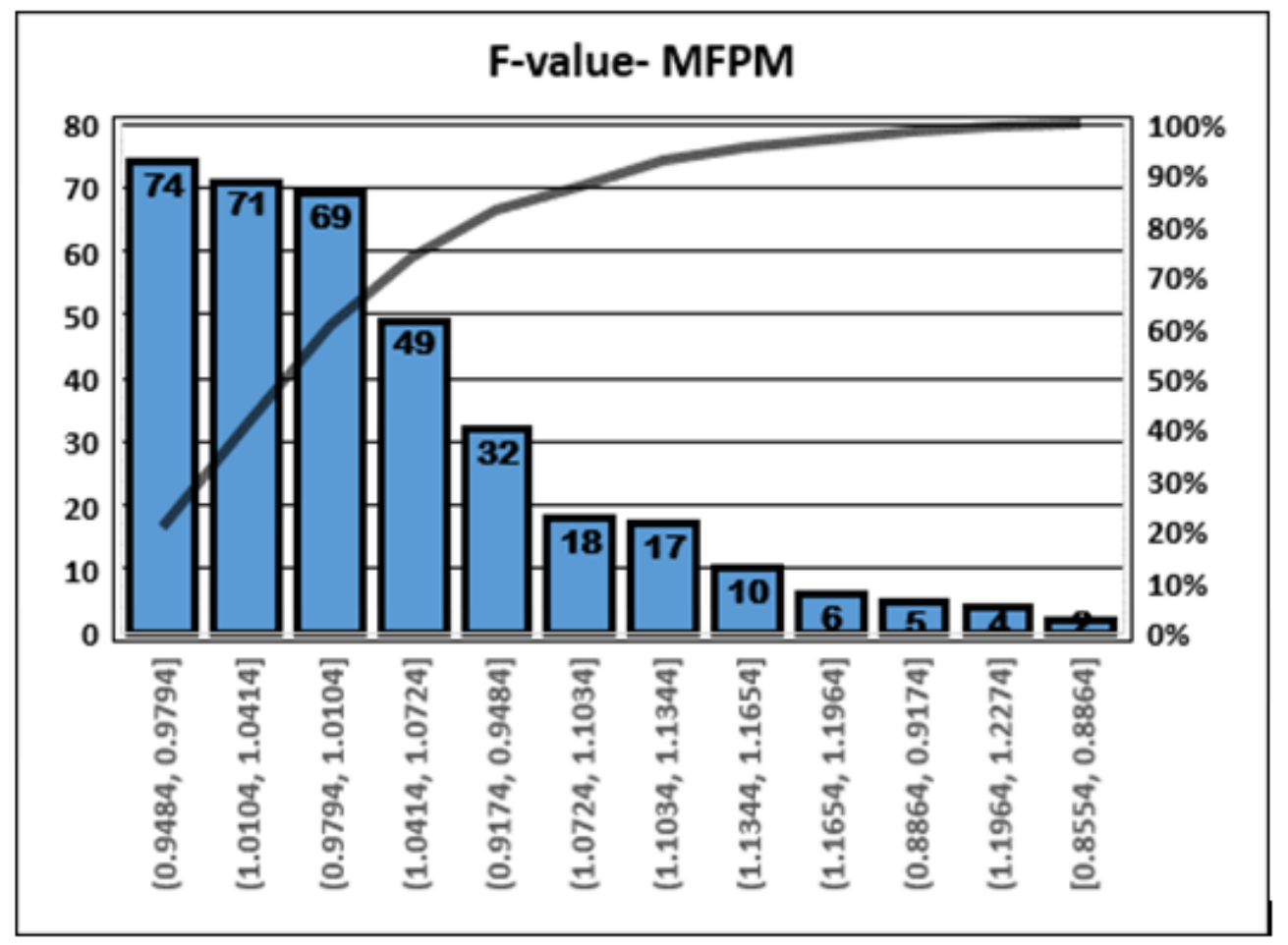

Fig. (2): Frequency distribution of the absolute intensity of $1001.03 \mathrm{keV}$ energy transition of the ${ }^{234 \mathrm{~m}} \mathrm{~Pa}$ using modified fundamental parameter (MFPM) method

\section{Conclusion}

Based on several published experimental as well as evolutional works, the commonly applied absolute intensity (I \%) of ${ }^{234 \mathrm{~m}} \mathrm{~Pa} 1001.03$ gamma-ray transition is about $0.847 \pm 0.008 \%$ with a wide range from 0.59 to 1.12 . The recent published $\mathrm{I} \%$ [36] revealed a new value of $1.037 \pm 0.052 \%$, using absolute efficiency method (AEM), that was about $22 \%$ higher than the commonly used value $(0.847 \pm 0.008 \%)$. While, using a relative method called fundamental parameter method (FPM) revealed $\mathrm{I} \%$ value of $1.0666 \pm 0.0834 \%$ with an average relative bias of $26 \%$ from the commonly used value. To confirm this newly revealed value, this study re-evaluated the I\% of $1001.03 \mathrm{keV}$ using the modified FPM (MFPM) and revealed the value of $1.0164 \pm 0.0636 \%$ that confirmed the previous findings.

\section{References}

1. Eberle, H., Matussek, P., Ottmar, H., Michel, P.I., Iyer, M.R., Chakraborthy, P.P., (1978). Non-destructive elemental and isotopic assay of plutonium and uranium in nuclear materials. In: Proceedings of
International Symposium on Nuclear Materials Safeguards.

2. Apostol, A.I., Pantelica, A., Sima, O., Fugaru, V., (2016). Isotopic composition analysis and age dating of uranium samples by high resolution gamma ray spectrometry. Nuclear Instruments and Methods in Physics Research Section B: Beam Interactions with Materials and Atoms, 383, 103-108.

3. Tohamy, M., El-Ghany, S. A., El-Minyawi, S. M., Fayez-Hassan, M., El-hakim, E. H., El-Mongy, S. A., Comsan, M. N. H., (2016). Passive Non-Destructive Assay based on gamma-ray spectrometry to verify $\mathrm{UO}_{2}$ samples in the form of powder and pellet. Annals of Nuclear Energy, 87, 186191.

4. Korob, R. O., Nuno, G. B., (2006). A simple method for the absolute determination of uranium enrichment by high-resolution $\gamma$ spectrometry. Applied radiation and isotopes, 64(5), 525-531.

5. Nguyen, C. T., Zsigrai, J., (2006). Basic characterization of highly enriched uranium by gamma spectrometry. Nuclear Instruments and Methods in Physics Research Section B: Beam Interactions with Materials and Atoms, 246(2), 417-424. 
6. Yücel, H. Cetiner, M.A. Demirel, H., (1998). Use of the $1001 \mathrm{keV}$ peak of ${ }^{234 \mathrm{~m}} \mathrm{~Pa}$ daughter of ${ }^{238} \mathrm{U}$ in measurement of uranium concentration by HPGe gammaray spectrometry. Nuclear Instruments and Methods in Physics Research A 413 (1998) 74-82.

7. Sengupta, A., Sankhe, R. H., \& Natarajan, V. (2015). Rapid and non-destructive determination of uranium and thorium by gamma spectrometry and a comparison with ICP-AES. Radioanalytical and Nuclear Chemistry, 306(2), 401-406.

8. Anilkumar, S., Deepa, A. K, Narayani, K., Rekha, A. K., Achuthan, P. V., Krishnamachari, G., Sharma, D. N., (2007). Estimation of ${ }^{235} \mathrm{U}$ concentration in some depleted uranium samples by high resolution gamma-ray spectrometry using $185 \mathrm{keV}$ and $1001 \mathrm{keV}$ gamma-energies of ${ }^{235} \mathrm{U}$ and ${ }^{234} \mathrm{mPa}$. Radioanalytical and Nuclear Chemistry, Vol. 274 (1), 161-166.

9. Kapsimalis, R., Landsberger, S., \& Reguigui, N. (2009). Measurement of uranium in small quantities in phosphates by use of $\gamma$-ray spectrometry and the 1001 $\mathrm{keV}$ peak of $234 \mathrm{mPa}$. Radioanalytical and Nuclear Chemistry, 280(2), 293-298.

10. Völgyesi, P., Kis, Z., Szabó, Z., \& Szabó, C. (2014). Using the $186-\mathrm{keV}$ peak for 226Ra activity concentration determination in Hungarian coal-slag samples by gammaray spectroscopy. Radioanalytical and Nuclear Chemistry, 302(1), 375-383.

11. Xhixha, G., Alberi, M., Baldoncini, M., Bode, K., Bylyku, E., Cfarku, F., Rodriguez, E., (2016). Calibration of HPGe detectors using certified reference materials of natural origin. Radioanalytical and Nuclear Chemistry, 307(2), 1507-1517.

12. Alharbi, S. H., Akber, R. A., Radioanalytical and Nuclear Chemistry 311(1), 59-75 (2017).

13. Naskar, N., Lahiri, S., Chaudhuri, P., Srivastava, A., Radioanalytical and Nuclear Chemistry, 310(3), 1381-1396 (2016).

14. http://www.nucleide.org/DDEP WG/Nucli des/Pa-234m tables.pdf

15. Coursol, N., Lagoutine, F. and Duchemin, B., Nuclear Instruments and Methods in Physics Research Section A: Accelerators, Spectrometers, Detectors and Associated Equipment 286(3), 589-594 (1990).

16. Bjornholm, S., Nielsen, O. B., Nuclear Physics 42, 642-659 (1963).

17. Gunnink, R., Tinney, J. F., (No. UCRL-51086). California Univ., Livermore. Lawrence Radiation Lab. (1971).
18. Momeni, M. H., Nuclear Instruments and Methods in Physics Research, 193(1-2), 185-190.

19. Moss, C. E. (1986). Gamma-ray line intensities for depleted uranium. Radiation Effects 94(1-4), 81-84 (1982).

20. Browne, E., Firestone, R. B., Shirley, V. S. (1986). Table of radioactive isotopes.

21. Scott, H. L., Marlow, K. W., (1990). Gamma-ray emission probabilities of the daughters of ${ }^{238} \mathrm{U}$. Nuclear Instruments and Methods in Physics Research Section A: Accelerators, Spectrometers, Detectors and Associated Equipment, 286(3), 549-555.

22. Jagam, P., Simpson, J., (1992). Intensity of the $1001 \mathrm{keV} \gamma$-ray in the decay of ${ }^{234 \mathrm{~m}} \mathrm{~Pa}$. Radioanalytical and nuclear chemistry, 166(5), 393-399.

23. Lin, W., Harbottle, G., (1992). Gamma-ray emission intensities of the ${ }^{232} \mathrm{Th}$ chain in secular equilibrium of ${ }^{235} \mathrm{U}$ and the progeny of ${ }^{238} \mathrm{U}$. Radioanalytical and nuclear chemistry, 157(2), 367-372.

24. Siemon, K., Esterlund, R. A., Van Aarle, J., Knaack, M., Westmeier, W., Patzelt, P., (1992). A new measurement of the gammaray intensities of $234 \mathrm{~m} \mathrm{~Pa}$ accompanying the decay of $238 \mathrm{U}$. International journal of radiation applications and instrumentation. Part A. Applied radiation and isotopes, 43(7), 873-880.

25. Sutton, G. A., Napier, S. T., John, M., Taylor, A., (1993). Uranium-238 decay chain data. Science of the total environment, 130, 393-401.

26. Duchemin, B., Coursol, N., Be, M. M., (1994). The re-evaluation of decay data for the U-238 chain. Nuclear Instruments and Methods in Physics Research Section A: Accelerators, Spectrometers, Detectors and Associated Equipment, 339(1), 146-150.

27. Firestone, R. B., Shirley, V. S., (1996). Table of Isotopes, vols. 1 and 2. John Willey \& Sons, Inc., New York.

28. Adsley, I., Backhouse, J. S., Nichols, A. L., \& Toole, J. (1998). U-238 decay chain: resolution of observed anomalies in the measured secular equilibrium between Th234 and daughter Pa-234m. Applied radiation and isotopes, 49(9), 1337-1344.

29. Nzuruba, A. C., (1999). Evaluation of absolute gamma ray emission probabilities in the decay of $234 \mathrm{mPa}$. Nuclear Instruments and Methods in Physics Research Section A: Accelerators, Spectrometers, Detectors and Associated Equipment, 424(2), 425-443. 
30. Anilkumar S., Narayani Krishnan, M.C. Abani, (1999). Application of fundamental parameter method for investigation of the branching intensity of $1001-\mathrm{keV}$ gamma energy of ${ }^{234 \mathrm{~m}} \mathrm{~Pa}$. Applied Radiation and Isotopes 51, 725-728

31. Ushakov, S. I., (2002). Abundance of 766.6 and $1001 \mathrm{keV} \gamma$-Quanta in the ${ }^{238} \mathrm{U}$ Decay Chain. Radiochemistry, 44(4), 313-314.

32. Yücel, H., Karadeniz, H., Çetiner, M., Demirel, H., Turhan, Ş., (2003). Measurement of absolute intensity of 1001 $\mathrm{keV}$ gamma-ray of ${ }^{234 \mathrm{~m}} \mathrm{~Pa}$. Radioanalytical and nuclear chemistry, 258(2), 445-447.

33. Al-Saleh, F. S. Al-Mukren, Al-J.H. Farouk, M.A., (2006). Precise determination of the absolute intensities of the gamma-ray lines of ${ }^{235} \mathrm{U}$ and some ${ }^{238} \mathrm{U}$ daughters. Nuclear Instruments and Methods in Physics Research A 568, 734-738

34. Browne, E., Tuli, J. K., (2007). Nuclear data sheets for $A=137$. Nuclear Data Sheets, 108(10), 2173-2318.

35. Begy, R. C., Cosma, C., Timar, A., Fulea, D., (2009). The Determination of Absolute Intensity of 234mPa's $1001 \mathrm{keV}$ Gamma Emission Using Monte Carlo Simulation. Journal of radiation research, 50(3), 277279

36. Ebaid, Y.Y. and Khater, A.E.M., (2017). The re-evaluation of the $234 \mathrm{~m}$ Pa's 1001.03 $\mathrm{keV}$ gamma emission absolute intensity for the precise assessment of $238 \mathrm{U}$. Journal of Environmental Radioactivity, 169, .203208.

37. Khater, A. E. M., Ebaid, Y. Y. (2017). The evaluation of the $1001.03 \mathrm{keV}$ gamma emission absolute intensity using fundamental parameter method. Journal of Environmental Radioactivity, 180, 120-126.

38. Be, M. M., Chechev, V. P. (2013). Recommended standards for gamma ray intensities. Nuclear Instruments and Methods in Physics Research Section A: Accelerators, Spectrometers, Detectors and Associated Equipment, 728, 157-172.

39. Delgado, J.U., Morel, J. and Etcheverry, M., (2002). Measurements of photon emission probabilities from the decay of $226 \mathrm{Ra}$ and daughters. Applied Radiation and Isotopes, 56(1), pp.137-143

40. IAEA, 2007. STI/PUB/1287, IAEA. Update of X-Ray and Gamma-Ray Decay Data Standards for Detector Calibration and Other Applications. Data Selection, Assessment and Evaluation Procedures, Vol. 2 VIENNA, 2007.

41. Manolopoulou, M., Mironaki, D., Papastefanou, C., 2003. A new technique for the accurate measurement of ${ }^{226} \mathrm{Ra}$ by gamma spectroscopy in voluminous samples. Nucl. Instrum. Methods Phys. Res. Sect. A Accel. Spectrom. Detect. Assoc. Equip. 508 (3), 362-366. 